\title{
Prevalência de Transtornos Mentais Comuns e Uso de Álcool e Drogas entre Agentes Penitenciários*
}

\author{
Ana Izabel Oliveira Lima ${ }^{1, * *}$, Magda Dimenstein², Rafael Figueiró ${ }^{1}$, \\ Jáder Leite ${ }^{2}, \&$ Cândida Dantas ${ }^{2}$ \\ ${ }^{1}$ Universidade Potiguar, Natal, RN, Brasil \\ ${ }^{2}$ Universidade Federal do Rio Grande do Norte, Natal, RN, Brasil
}

\begin{abstract}
RESUMO - Investigou-se a prevalência de Transtornos Mentais Comuns e uso de drogas entre Agentes Penitenciários de um estado da região Nordeste do Brasil. Um total de 403 trabalhadores respondeu ao SRQ-20, ASSIST e ao roteiro de entrevista semiestruturada. Os resultados apontam para a prevalência de 23,57\% de TMC e consumo abusivo/dependente em tabaco (35,9\%), álcool (88,3\%), maconha (10,5\%), cocaína (3,6\%), anfetamina $(1,1 \%)$, inalantes $(7,6 \%)$, hipnóticos $(4,4 \%)$ e alucinógenos $(0,3 \%)$. Apresentam-se como determinantes desse quadro: tipo de unidade prisional, ter outra ocupação na área de segurança, ter mais de 10 anos de profissão e trabalhar em turnos dobrados. Esse quadro é desafiador, tanto para as políticas de saúde do trabalhador no âmbito prisional quanto para os psicólogos que atuam nesse âmbito, devido aos impactos na vida dos agentes.
\end{abstract}

PALAVRAS chave: sistema prisional, agentes penitenciários, condições de trabalho, saúde mental, álcool e drogas

\section{Prevalence of Common Mental Disorders and Alcohol and Substance Abse Among Correctional Officers}

\begin{abstract}
We investigated the prevalence of Common Mental Health Disorders (CMD) and substance abuse among correctional officers in a northeastern state of Brazil. In the study, 403 workers answered the SRQ-20, the ASSIST questionnaire and a semistructured interview script. Results show an incidence of $23.57 \%$ of CMD and abuse/dependence in tobacco (35.9\%), alcohol (88.3\%), marijuana (10.5\%), cocaine (3.6\%), amphetamine (1.1\%), inhalants (7.6\%), hypnotics $(4.4 \%)$ and hallucinogens $(0.3 \%)$. The determinant factors are: type of detention facility, having another occupation in the field of security, over 10 years in the profession and working double shifts. This is challenging not only in terms of providing health care for correctional officers, but also to psychologists working in this field due to how it affects the lives of those workers.
\end{abstract}

KEYWORDS: penitentiary system, correctional officers, work conditions, mental health, alcohol and drugs

O trabalho do agente penitenciário (AP), comumente conhecido como carcereiro, é, muitas vezes, associado a uma das mais indesejáveis ocupações (Lourenço, 2012). Estudos sobre essa categoria profissional são raros e geralmente associados à história da prisão (Lopes, 2007). Varella (2012), no livro Carcereiros, revela a dificuldade de encontrar pessoas que cumprissem essa função nas prisões paulistas do século XIX, o que resultou em pressões populares para que a Câmara de São Paulo "obrigasse algum cidadão a aceitar o cargo" (Varella, 2012, p. 37).
Os APs têm a função de custodiar os presos, sendo responsáveis pelas tarefas de revista (tanto dos presos quanto dos visitantes e das celas), de condução de presos (na área interna e externa da unidade prisional) e pela vigilância da mesma. Nem todos os trabalhadores exercem as mesmas funções, o que pode significar sobrecarga, sobretudo, para aqueles que lidam mais diretamente com presos nos pavilhões ou executam revista de familiares (Vasconcelos, 2000). Os APs estão constantemente expostos a situações de estresse, tais como intimidações, agressões, ameaças e

\footnotetext{
* Apoio: $\mathrm{CNPq}$

** E-mail: anaizabel.psi@gmail.com

n Submetido: 23/12/2015; Revisado: 14/10/2017; Aceito: 16/02/2018.
} 
possibilidades de rebeliões, que ameaçam sua integridade física (Fernandes et al., 2002). O trabalho em instituições prisionais envolve, dessa maneira, permanente e intenso controle emocional, além de elevada responsabilidade com vidas humanas, realização de tarefas em situação de confinamento e de relações grupais tensas, bem como situações de controle e disciplina rigidamente hierarquizadas (Lourenço, 2010). O risco e a vulnerabilidade são, portanto, inerentes ao trabalho no cárcere (Lourenço, 2012).

Entre os fatores indesejáveis associados à profissão, podemos destacar o pouco reconhecimento social, a baixa remuneração, relações fortemente hierarquizadas nas instituições e ausência de poder de decisão em determinadas situações, como em rebeliões, por exemplo (Kalinsky, 2008). Além disso, a superlotação da maior parte das unidades prisionais do país e relações tensas entre colegas se constituem como fatores de risco para o trabalho no cárcere. Ademais, o AP precisa, muitas vezes, lidar com situações para o qual não foi preparado: síndromes de abstinência (álcool ou outras drogas), transtorno mental, HIV, tuberculose e até mesmo com reações emocionais dos detentos frente ao abandono familiar ou sentenças proferidas (Santos et al., 2010). Assim, a categoria de agente penitenciário pode ser classificada como uma ocupação arriscada e estressante, podendo levar a distúrbios físicos e psicológicos.

Não apenas a literatura internacional (Kalinsky, 2008; Ghaddar, Mateo, \& Sanchez, 2008), mas também a nacional (Lourenço, 2010; Lopes, 2007; Fernandes et al. 2002) vêm apontando para o elevado índice de adoecimento psíquico (estresse, alcoolismo, transtornos mentais), que marca o cotidiano laboral dessa categoria. Aliada a isso, a superlotação e a carência de trabalhadores nas unidades prisionais acabam por agravar a situação, provocando desgaste físico e mental (Lopes, 2007). Na pesquisa desenvolvida por Vasconcelos (2000) com agentes penitenciários do Rio de Janeiro, o autor identificou uma série de nomenclaturas para designar um "conjunto de ansiedades, receios e insatisfações decorrentes das exigências do trabalho", tais como "nervos abalados", "esquentamento de cabeça", "mente perturbada", "neurose de cadeia" (p. 43), o que demonstra o quão delicada é a questão da saúde mental, não apenas para essa categoria profissional, mas para todos os profissionais da segurança pública (Vasconcelos, 2000).
Dados mostram que 30\% dos trabalhadores em presídios apresentam consumo elevado de bebidas alcoólicas, e um em cada dez sofre de transtorno psicológico (Luiz, 2003). Em estudo realizado com agentes penitenciários da região metropolitana de Salvador/BA, Fernandes et al. (2002) encontraram prevalência de transtornos mentais comuns (TMC) de 30,7\% e estresse persistente, todos associados às condições e características do trabalho no cárcere. $\mathrm{Na}$ mesma pesquisa, os autores encontraram que $68,5 \%$ dos APs entrevistados fazem uso de álcool e 15,6\% apresentam suspeita de alcoolismo.

Os transtornos mentais comuns, também chamados de transtorno mental não psicótico, dizem respeito a um conjunto de sintomas decorrentes de atividades consideradas estressoras que são desempenhadas no dia-a-dia. De acordo com Goldberg e Huxley (1992), esses sintomas englobam insônia, fadiga, irritabilidade, esquecimento, dificuldade de concentração e queixas somáticas. Estima-se que até 2030 os TMC estejam entre as perturbações mais incapacitantes (Skapinakis et al., 2013). Estudos de base populacional realizados em países industrializados mostram que a prevalência de TMC pode variar de 7\% a 30\% (Goldberg \& Huxley, 1992).

Apesar das evidências relacionadas às condições inadequadas no processo de trabalho, há poucos estudos que informam sobre o adoecimento de agentes de segurança penitenciária, conhecimento importante para o estabelecimento de políticas públicas e o planejamento de serviços de atenção à saúde. Este trabalho mostra os resultados de uma pesquisa realizada em um estado do Nordeste brasileiro, cujo objetivo geral foi mapear a prevalência de transtornos mentais comuns e uso de álcool e outras drogas entre os agentes penitenciários trabalhadores do sistema prisional do estado. Como objetivos específicos, definiu-se: delinear o perfil dos trabalhadores do sistema prisional, a partir das variáveis sexo, renda, estado civil, escolaridade; identificar o tipo de relação do AP com o trabalho e conhecer os recursos formais (rede de saúde, assistência social, justiça) e informais utilizados pelos agentes penitenciários no cuidado em saúde, especificamente em relação aos problemas associados ao uso de álcool e transtornos mentais comuns.

\section{MÉTODO}

Esta pesquisa caracteriza-se como um estudo quantitativo, ou seja, busca enfatizar o desenvolvimento da investigação dentro de protocolos estabelecidos e técnicas específicas, realizando uma descrição quantitativa ou numérica de tendências, atitudes ou comportamentos de uma população ao estudar uma amostra dela (Creswell, 2007).

\section{Local e Participantes da Pesquisa}

Após autorização pela gestão do sistema prisional estadual, bem como pelo comitê de ética local (parecer número 760.701 ), foram selecionadas as unidades prisionais e os participantes da pesquisa. O Estado conta 
com 34 unidades prisionais (nove penitenciárias estaduais, uma penitenciária federal, uma unidade psiquiátrica de custódia e tratamento, três cadeias públicas e 20 Centros de Detenção Provisória), aproximadamente 7.200 presos, custodiados por 902 agentes penitenciários. Utilizamos como critério de escolha: (1) unidades prisionais destinadas a presos já sentenciados e, (2) devido ao grande número de Centros de Detenção Provisória (CDP) no Estado, foram eleitos os CDPs com maiores índices de fugas, motins e intervenções da vigilância sanitária diante das condições estruturais e de insalubridade (de acordo com dados fornecidos pela Secretaria de Estado da Justiça e da Cidadania/SEJUC). Os CDPs têm por função custodiar presos temporariamente, apresentando-se como uma unidade de ingresso e classificação para o sistema prisional estadual, diferenciando-se das penitenciárias que se destinam aos presos já condenados para o cumprimento de pena de reclusão, sendo esta em regime fechado ou semiaberto.

Dessa forma, participaram do estudo 19 unidades prisionais: 12 penitenciárias (seis estão localizadas na capital do estado, quatro ficam da região oeste, uma na região agreste e uma na região central); uma Unidade Psiquiátrica de Custódia e Tratamento (localizada na capital do estado); uma Penitenciária Federal (localizada na região oeste do estado); cinco Centros de Detenção Provisória (todas localizadas na capital). Do total de agentes penitenciários (902), 403 participaram da coleta de dados, ou seja, são agentes que trabalham nas Unidades Prisionais acima destacadas, de ambos os sexos e que aceitaram participar da pesquisa através da assinatura de Termo de Consentimento Livre e Esclarecido (TCLE). Constituíram-se como critérios de exclusão: a recusa em participar da pesquisa e existência de condição médica ou psicológica que impossibilitasse a participação.

\section{Instrumentos}

Como ferramentas, utilizamos o Self-Reporting Questionnaire (SRQ-20) desenvolvido pela Organização Mundial de Saúde (WHO, 1994) para rastreamento de TMC. O instrumento consiste em 20 questões relacionadas à condição de saúde mental nos últimos trinta dias, com resposta simples ( $\operatorname{sim} /$ não). Cada resposta SIM equivale a um ponto, podendo variar, portanto, de zero (nenhuma probabilidade de TMC) a 20 (extrema probabilidade de TMC). Consideramos, nesta pesquisa, o ponto de corte $\geq 7$ (Gonçalves, Stein, \& Kapczinsk, 2008). O segundo instrumento utilizado foi o ASSIST (Alcohol, Smoking and Substance Involvement Screening Test), igualmente desenvolvido pela Organização Mundial de Saúde (WHO, 2002), sendo um método simples de triagem do uso de risco, nocivo ou dependente de tabaco, álcool, maconha (cannabis), cocaína, anfetaminas, sedativos, alucinógenos, inalantes, opiáceos e outras drogas. Esse método consiste em oito questões que avaliam o consumo dessas substâncias nos últimos 3 meses. De acordo com Henrique, Micheli, Lacerda, Lacerda e Formigoni (2004), o estudo da confiabilidade teste-reteste do ASSIST foi realizado com 236 indivíduos, em diferentes locais do mundo, sendo observado bom nível de confiança (coeficientes Kappa entre 0,58 a 0,90 para as principais questões). Além disso, foi aplicado questionário sociodemográfico com intuito de obter dados para compor o perfil dos agentes: sexo, renda, estado civil, escolaridade, relação com o trabalho e cuidado com a saúde mental.

\section{Procedimentos}

A coleta de dados ocorreu entre os meses de outubro de 2014 e janeiro de 2015. As três ferramentas foram aplicadas individualmente e os pesquisadores passaram por treinamento antes de iniciar a coleta de dados, com a realização de uma etapa piloto com a participação de 15 agentes penitenciários da Unidade Psiquiátrica de Custódia e Tratamento. Tal unidade inicialmente não fazia parte deste estudo por não se configurar somente como uma unidade prisional, mas também como um local de tratamento destinado às pessoas com transtorno mentais que cometeram atos infracionais. No entanto, depois de testado o instrumento, foi possível constatar sua aplicabilidade e os trabalhadores dessa instituição passaram a compor a amostra final da pesquisa.

\section{Análise de Dados}

Os dados coletados foram analisados através do programa SPSS (Statistical Package for the Social Sciences - pacote estatístico para as ciências sociais, versão 20), em termos de frequência absoluta e percentual, utilizando o teste Qui-quadrado $\left(\chi^{2}\right)$ para investigar se existe relação de dependência entre as variáveis contrastadas. Esse teste investiga a associação entre as variáveis contrastadas, comparando os valores observados (valores reais) com os valores que deveriam ser esperados, considerando que as variáveis são independentes. Nos testes aplicados, o índice de significância adotado foi de $5 \%$.

\section{RESULTADOS}

\section{Perfil dos Participantes}

Participaram da pesquisa 403 agentes penitenciários, dos quais 66 estão lotados nos 05 Centros de Detenção
Provisória e 337 em 14 penitenciárias. Como é possível observar na tabela $1,90,6 \%$ eram do sexo masculino, com tempos de trabalhos distintos: $53,3 \%$ com até 5 anos de trabalho e $39,2 \%$ entre 10 e 15 anos. Com relação à 
Tabela 1

Perfil da Amostra

\begin{tabular}{|c|c|c|}
\hline Variáveis & Especificações & Frequência $(\%)$ \\
\hline Unidade Prisional & $\begin{array}{c}\text { Centro de Detenção Provisória } \\
\text { Penitenciária }\end{array}$ & $\begin{array}{c}66(16,4) \\
337(83,6)\end{array}$ \\
\hline Sexo & $\begin{array}{l}\text { Masculino } \\
\text { Feminino }\end{array}$ & $\begin{array}{c}365(90,6) \\
38(9,4)\end{array}$ \\
\hline Tempo de trabalho & $\begin{array}{c}0 \text { a } 5 \text { anos } \\
5 \text { a } 10 \text { anos } \\
10 \text { a } 15 \text { anos }\end{array}$ & $\begin{array}{c}215(53,3) \\
30(7,4) \\
158(39,2)\end{array}$ \\
\hline Idade & $\begin{array}{l}20 \text { a } 25 \text { anos } \\
25 \text { a } 30 \text { anos } \\
30 \text { a } 35 \text { anos } \\
35 \text { a } 40 \text { anos } \\
40 \text { a } 45 \text { anos } \\
45 \text { a } 50 \text { anos } \\
50 \text { a } 55 \text { anos }\end{array}$ & $\begin{array}{c}7(1,7) \\
79(19,6) \\
106(26,6) \\
87(21,6) \\
69(17,1) \\
43(10,7) \\
12(3)\end{array}$ \\
\hline Estado Civil & $\begin{array}{c}\text { Solteiro } \\
\text { Casado ou em união estável } \\
\text { Separado }\end{array}$ & $\begin{array}{c}115(28,5) \\
257(63,7) \\
31(7,7)\end{array}$ \\
\hline Número de filhos & $\begin{array}{c}\text { Não tem } \\
1 \\
2 \\
3 \text { ou mais }\end{array}$ & $\begin{array}{l}122(30,3) \\
117(29) \\
112(27,8) \\
52(12,9)\end{array}$ \\
\hline Religião & $\begin{array}{c}\text { Católico } \\
\text { Protestante } \\
\text { Espírita } \\
\text { Umbanda/candomblé } \\
\text { Sem religião } \\
\text { Outra }\end{array}$ & $\begin{array}{c}238(59,1) \\
77(19,1) \\
11(2,7) \\
2(0,5) \\
17(4,2) \\
58(14,4)\end{array}$ \\
\hline Renda familiar & $\begin{array}{l}2 \text { a } 3 \text { salários mínimos } \\
4 \text { a } 5 \text { salários mínimos } \\
6 \text { a } 7 \text { salários mínimos } \\
8 \text { a } 9 \text { salários mínimos } \\
\text { Acima de } 10 \text { salários mínimos }\end{array}$ & $\begin{array}{l}22(5,5) \\
214(53,1) \\
62(15,4) \\
38(9,4) \\
67(16,6)\end{array}$ \\
\hline Escolaridade & $\begin{array}{l}\text { Ensino médio completo } \\
\text { Ensino Superior incompleto } \\
\text { Ensino superior completo } \\
\text { Pós-Graduação }\end{array}$ & $\begin{array}{c}85(21,1) \\
91(22,6) \\
205(50,6) \\
22(5,5)\end{array}$ \\
\hline Possui outra ocupação? & $\begin{array}{l}\text { Sim } \\
\text { Não }\end{array}$ & $\begin{array}{c}88(21,8) \\
315(78,2)\end{array}$ \\
\hline Qual é essa outra ocupação? & $\begin{array}{c}\text { Na área de segurança } \\
\text { Outra área }\end{array}$ & $\begin{array}{l}15(17,0) \\
73(83,0)\end{array}$ \\
\hline Dobra de turno no último mês & $\begin{array}{c}\text { Nenhuma vez } \\
1 \text { vez } \\
2 \text { vezes } \\
3 \text { vezes } \\
4 \text { ou mais vezes }\end{array}$ & $\begin{array}{c}260(64,5) \\
41(10,2) \\
30(7,4) \\
47(11,7) \\
25(6,2)\end{array}$ \\
\hline Recursos de cuidado em saúde mental já procurados & $\begin{array}{l}\text { Nunca procurou } \\
\text { Atenção básica } \\
\text { CAPS } \\
\text { Psiquiatra, Psicólogo } \\
\text { Grupo da igreja }\end{array}$ & $\begin{array}{c}310(76,9) \\
4(1,0) \\
2(0,5) \\
70(17,4) \\
17(4,2)\end{array}$ \\
\hline
\end{tabular}

idade dos participantes, a maioria $(84,9 \%)$ tem entre 25 e 45 anos. Quanto ao estado civil dos entrevistados, $63,7 \%$ declararam estar em relacionamento estável, $56,8 \%$ têm até dois filhos, 95,8\% possuem alguma religião (em sua maioria católicos, $59,1 \%$ ) e $68,5 \%$ têm renda familiar entre 4 e 7 salários mínimos. Com relação à escolaridade, 50,6\% possuem ensino superior completo e $20,1 \%$ estão cursando o $3^{\circ}$ grau. Outras informações relevantes indicam que 78,2\% não possuem outra ocupação, $64,5 \%$ não dobraram de turno no último mês (porém, 17,9\% dobraram mais de três vezes) e $76,9 \%$ nunca buscaram ajuda em saúde mental. 


\section{Prevalência de Transtorno Mental Comum entre Agentes Penitenciários}

A prevalência de TMC foi de $23,57 \%$ (tabela 2), percentual dentro da média encontrada em alguns estudos realizados no Brasil (entre 28,7\% a 50\%) (Lucchese, Souza, Bonfin, Vera, \& Santana, 2014) com outras categorias profissionais. A pesquisa de Fernandes et al. (2002) encontrou prevalência de $30,7 \%$ de TMC nos APs investigados na região metropolitana de Salvador/BA, número maior do que entre policiais região metropolitana de Florianópolis/SC (23\%), professores da rede particular de ensino $(20,1 \%)$, metalúrgicos $(19 \%)$ e trabalhadores de processamentos de dados (19 a 24\%) (Lima, Blank, \& Menegon, 2015; Rodrigues, Rodrigues, Oliveira, Laudano, \& Sobrinho, 2014).

Pode-se observar que não há diferença significativa entre os percentuais de agentes que ultrapassaram o ponto de corte nas penitenciárias $(24,04 \%)$ e nos Centros de Detenção Provisória (21,21\%). Os APs que apresentam indicativo de TMC trabalham, em sua maioria, na Unidade Psiquiátrica de Custódia e Tratamento $(43,75 \%)$, na penitenciária estadual localizada na região central $(46,51 \%)$ e na penitenciária federal ( $36 \%)$. Referindo-se às atividades nessas instituições, agentes da penitenciária federal apontaram como característica principal do trabalho o "ócio intelectual" diante da falta de controle sobre sua rotina no trabalho, pouco contato com o preso (com a automatização não precisa entrar no pavilhão para abrir as celas), e rigidez dos procedimentos estabelecidos pelo Governo Federal na organização das condições do trabalho. A rotina monótona e o ócio parecem deflagrar sentimento de vazio, ineficiência, tristeza, frustração, que geram ideação suicida. Já o Hospital de Custódia é marcado pela falta de treinamento para lidar com a loucura e o trabalho é atravessado pela "imprevisibilidade e periculosidade do louco/criminoso".

O CDP que apresentou maior índice de TMC é o da zona sul da capital $(26,67 \%)$. Essa unidade é o centro de triagem dos presos da região metropolitana da capital. Os APs que trabalham nesse local têm sua rotina diária marcada por um intenso convívio carcerário, recepcionam custodiados, fazem escoltas, acompanham presos aos fóruns e tribunais, além de receberem constantemente visitas de advogados e oficiais da justiça, indicando intenso desgaste laboral.

Dentre os agentes que estão acima do ponto de corte, $48,42 \%$ trabalham no sistema entre 10 a 15 anos, $71,58 \%$ têm entre 30 e 45 anos, $62,11 \%$ estão casados, $62,11 \%$ têm um ou dois filhos, $50 \%$ são católicos, $45,26 \%$ têm ensino superior completo, $30,53 \%$ possuem outra ocupação, $31,03 \%$ têm outra ocupação na área de segurança, 33,68\% dobraram de turno no último mês e $62,11 \%$ nunca procuraram cuidado em saúde mental. Em relação às dimensões do SRQ-20, foi possível perceber que quase metade dos agentes afirmou dormir mal (40\%), que o trabalho causa sofrimento diário $(40 \%)$ e que se sente constantemente nervoso, tenso e preocupado (43\%), atingindo maiores pontuações em questões relacionadas ao humor depressivo ansioso $(59,55 \%$ - dor de cabeça, dormir mal, desconforto estomacal, má digestão, falta de apetite, tremores) e sintomas somáticos $(53,35 \%$ - nervoso, assustam-se com facilidade, tristeza, choram com mais frequência).

Constatamos associação positiva entre ter outra ocupação e atingir o ponto de corte para TMC $\left(\mathrm{X}^{2}(1)=5,500 ; \mathrm{p}=\right.$ $0,019)$. Um agravante é o fato de possuir outra ocupação na área de segurança, situação que aumenta a probabilidade de desenvolver TMC $\left(\mathrm{X}^{2}(1)=5,986 ; \mathrm{p}=0,014\right)$.

Com relação ao tempo de trabalho, embora o teste do qui quadrado revele o valor de $p=0,09$, ou seja, maior que 0,05 , foi detectada prevalência de TMC em sujeitos com tempo de trabalho maior que 5 anos (sobretudo de 10 a 15 anos de profissão), corroborando os achados de Alves (2009), que evidenciaram maior prevalência de TMC entre os APs com mais de 9 anos de profissão.

Outro ponto importante das análises diz respeito à dobra de turno ${ }^{1}$, prática comum entre os APs. A pesquisa

1 Dobrar turno é o a maneira como os agentes nomeiam a prática de trabalhar 48hs seguidas (ao invés de 24hs). Muitos agentes dobram turnos, seja para ganhar uma renda extra (quando recebem do colega pelo turno trabalhado em seu lugar), seja para aumentar os dias de folga (prática muito comum em unidades prisionais do interior do estado, onde os AP trabalham $48 \mathrm{hs}$ e folgam seis dias, diminuindo o tempo perdido com o traslado, e aumentando o tempo de descanso), ou mesmo para realizar um favor a algum colega que não pode comparecer ao trabalho.

Tabela 2

Prevalência de Transtornos Mentais Comuns

\begin{tabular}{|c|c|c|c|c|}
\hline & & & $\mathbf{N}$ & $\%$ \\
\hline Penitenciária & Ponto de corte & $\begin{array}{c}\text { abaixo do ponto de corte } \\
\text { acima do ponto de corte } \\
\text { Total }\end{array}$ & $\begin{array}{c}256 \\
81 \\
337\end{array}$ & $\begin{array}{r}75,96 \% \\
24,04 \% \\
100,00 \%\end{array}$ \\
\hline CDP & Ponto de corte & $\begin{array}{c}\text { abaixo do ponto de corte } \\
\text { acima do ponto de corte } \\
\text { Total }\end{array}$ & $\begin{array}{l}52 \\
14 \\
66\end{array}$ & $\begin{array}{c}78,79 \% \\
21,21 \% \\
100,00 \%\end{array}$ \\
\hline Total & Ponto de corte & $\begin{array}{c}\text { abaixo do ponto de corte } \\
\text { acima do ponto de corte } \\
\text { Total }\end{array}$ & $\begin{array}{c}308 \\
95 \\
403\end{array}$ & $\begin{array}{r}76,43 \% \\
23,57 \% \\
100,00 \%\end{array}$ \\
\hline
\end{tabular}

Nota. O ponto de corte adotado para determinar transtorno mental comum foi $\geq 7$ respostas positivas 
não encontrou associação positiva entre essa variável e a prevalência de TMC $\left(\mathrm{X}^{2}(4)=4,46 ; \mathrm{p}=0,34\right)$. No entanto, os dados brutos da pesquisa, bem como os da literatura (Fernandes et al., 2002; Lourenço, 2010; Souza \& Rumin, 2013) indicam que a permanência no âmbito do trabalho por maior tempo do que o planejado é um fator disparador muito importante e tem estreita relação com a saúde mental de agentes penitenciários.

Além dessas variáveis, aqueles agentes que possuem estado civil "casado" ou "união estável" apresentaram maior probabilidade de atingirem o ponto de corte para TMC. Por fim, os dados evidenciaram associação entre os APs que ficaram acima do ponto de corte e o fato de já ter buscado cuidado em saúde mental, indicando a necessidade de maior investigação sobre como se dá essa busca, assim como que estratégias podem ser pensadas para facilitar o acolhimento desse trabalhador na rede de cuidados básica e especializada.

\section{Padrão de Uso de Álcool e Outras Drogas entre Agentes Penitenciários}

Em relação ao padrão de uso de álcool e outras drogas, das nove substâncias que o ASSIST investiga, oito foram citadas como já utilizadas pelos APs: tabaco (baixo risco $27,3 \%$-, uso nocivo - $8,19 \%$ - e uso dependente $-0,5 \%$ ), álcool (baixo risco - 66\% - uso nocivo - $21,84 \%$-, uso dependente $-0,5 \%$ ), maconha (baixo risco $-9,1 \%-$, uso nocivo $-1,49 \%$-, uso dependente $-0,25 \%$ ), cocaína (baixo risco $-2,98 \%$-, uso nocivo - $0,74 \%$ ), anfetamina (baixo risco $-0,99 \%$-, uso nocivo - $0,25 \%$ ), inalantes (baixo risco $-7,44 \%$-, uso nocivo - 0,25\%), hipnóticos (baixo risco $3,72 \%$-, uso nocivo - $0,25 \%$, uso dependente - $0,5 \%$ ) e, em menor escala, alucinógenos (baixo risco - 0,3\%).

Há diferenças em relação ao uso de substâncias quanto ao tipo de unidade prisional (tabela 3). Os dados indicam que o trabalho em CDP possui associação positiva com o uso nocivo ou dependente em álcool $\left(X^{2}(1)=20,540 ; p=0,00\right)$ e tabaco $\left(\mathrm{X}^{2}(1)=6,370 ; \mathrm{p}=0,041\right)$, bem como entre tempo de trabalho e o consumo de maconha $\left(X^{2}(1)=12,316\right.$; $\mathrm{p}=0,015)$. Pessoas que trabalham no sistema há mais de 10 anos mostram-se mais propensas ao consumo abusivo/ dependente de cannabis. Por fim, possuir outra ocupação na área de segurança aumenta as chances de uso nocivo ou dependente de tabaco $\left(\mathrm{X}^{2}(1)=6,470 ; \mathrm{p}=0,039\right)$ e álcool $\left(\mathrm{X}^{2}\right.$ $(1)=12,744 ; p=0,02)$.

Tabela 3

Consumo de Substâncias Psicoativas por Unidade Prisional

\begin{tabular}{|c|c|c|c|}
\hline Substância & Resultado do ASSIST & Penitenciária n (\%) & CDP n (\%) \\
\hline Tabaco & $\begin{array}{c}\text { Baixo risco } \\
\text { Uso nocivo/dependente } \\
\text { Nunca usaram } \\
\text { Total }\end{array}$ & $\begin{array}{c}93(27,6 \%) \\
24(7,12 \%) \\
220(65,28 \%) \\
337(100 \%)\end{array}$ & $\begin{array}{c}17(25,76 \%) \\
11(16,67) \\
38(57,58 \%) \\
66(100 \%)\end{array}$ \\
\hline Álcool & $\begin{array}{c}\text { Baixo risco } \\
\text { Uso nocivo/dependente } \\
\text { Nunca usou } \\
\text { Total }\end{array}$ & $\begin{array}{l}238(70,62 \%) \\
63(18,69 \%) \\
36(10,68 \%) \\
337(100 \%)\end{array}$ & $\begin{array}{c}28(42,42 \%) \\
27(40,91 \%) \\
11(16,67 \%) \\
66(100 \%)\end{array}$ \\
\hline Maconha & $\begin{array}{c}\text { Baixo risco } \\
\text { Uso nocivo/dependente } \\
\text { Nunca usou } \\
\text { Total }\end{array}$ & $\begin{array}{c}30(8,9 \%) \\
4(1,19 \%) \\
303(89,91 \%) \\
337(100 \%)\end{array}$ & $\begin{array}{c}7(10,61 \%) \\
3(4,55 \%) \\
56(84,85 \%) \\
66(100 \%)\end{array}$ \\
\hline Cocaína & $\begin{array}{c}\text { Baixo risco } \\
\text { Uso nocivo/dependente } \\
\text { Nunca usou } \\
\text { Total }\end{array}$ & $\begin{array}{c}7(2,08 \%) \\
0 \\
330(97,92 \%) \\
337(100 \%)\end{array}$ & $\begin{array}{c}5(7,58 \%) \\
3(4,55 \%) \\
58(87,88 \%) \\
66(100 \%)\end{array}$ \\
\hline Anfetaminas & $\begin{array}{c}\text { Baixo risco } \\
\text { Uso nocivo/dependente } \\
\text { Nunca usou } \\
\text { Total }\end{array}$ & $\begin{array}{c}3(0,89 \%) \\
0 \\
334(99,11 \%) \\
337(100 \%)\end{array}$ & $\begin{array}{c}1(1,52 \%) \\
0 \\
1(1,52 \%) \\
66(100 \%)\end{array}$ \\
\hline Inalantes & $\begin{array}{c}\text { Baixo risco } \\
\text { Uso nocivo/dependente } \\
\text { Nunca usou } \\
\text { Total }\end{array}$ & $\begin{array}{c}21(6,23 \%) \\
1(0,3 \%) \\
315(93,47 \%) \\
337(100 \%)\end{array}$ & $\begin{array}{c}9(13,64 \%) \\
0 \\
57(86,36 \%) \\
66(100 \%)\end{array}$ \\
\hline Hipnóticos & $\begin{array}{c}\text { Baixo risco } \\
\text { Uso nocivo/dependente } \\
\text { Nunca usou } \\
\text { Total }\end{array}$ & $\begin{array}{c}7(2,08 \%) \\
1(0,3 \%) \\
329(97,63 \%) \\
337(100 \%)\end{array}$ & $\begin{array}{c}8(12,12 \%) \\
2(3,04 \%) \\
56(84,85 \%) \\
66(100 \%)\end{array}$ \\
\hline Alucinógenos & $\begin{array}{c}\text { Baixo risco } \\
\text { Uso nocivo/dependente } \\
\text { Nunca usou } \\
\text { Total }\end{array}$ & $\begin{array}{c}1(0,3 \%) \\
0 \\
336(99,70 \%) \\
337(100 \%)\end{array}$ & $\begin{array}{c}0 \\
0 \\
66(100 \%) \\
66(100 \%)\end{array}$ \\
\hline
\end{tabular}


Os APs dos CDPs, mesmo em número menor na pesquisa que os trabalhadores das penitenciárias, apresentaram padrão de consumo abusivo/dependente acima da média nacional (mn) em algumas substâncias, quando comparado aos resultados do II Levantamento Nacional de Drogas (INPAD, 2013). São elas: álcool (40,9\%, mn é 16\%), maconha (4,55\%, mn é $2,5 \%)$, crack/cocaína ( $4,55 \%$; mn é $1,7 \%)$ e anfetamina (1,52\%; mn é $1,1 \%)$. As penitenciárias apresentam consumo abusivo/dependente acima da média nacional somente em relação ao álcool $(18,7 \%)$. As unidades prisionais que mais se destacam no consumo das substâncias citadas foram a Penitenciária Federal (tabaco, álcool, maconha e cocaína/crack), o CDP da zona sul da capital (álcool, maconha, cocaína/crack, hipnóticos), a penitenciária da região oeste do estado (tabaco), Unidade Psiquiátrica de Custódia e Tratamento (álcool e inalante) e penitenciária da região central do estado (alucinógeno e inalante). Os APs que apresentam consumo nocivo/dependente se assemelham ao perfil de trabalhadores com indicativo de TMC: maior tempo de trabalho (10 a 15 anos), ensino superior completo, outra ocupação de área de segurança e dobra de turno no último mês.

\section{DISCUSSÃO}

Os resultados encontrados nesse estudo se assemelham aos demonstrados em outras pesquisas que objetivaram investigar as consequências do trabalho na saúde mental de agentes de segurança penitenciária (Santos et al, 2010; Souza \& Rumin, 2013; Lourenço, 2010). Tais estudos apontaram a presença de sofrimento mental em agentes jovens, com pouco tempo de trabalho, que precisam complementar a renda, seja com outra ocupação, seja dobrando de turno. Eles corroboram nossos achados, os quais indicam que os agravos em saúde mental vivenciados pelos trabalhadores de prisões são diretamente decorrentes das características do processo, das condições e da organização do trabalho. Em outras palavras, o quadro de adoecimento psíquico detectado está relacionado ao fato de que, geralmente, os APs estão sob intensa vigília, têm jornadas de trabalho longas, com poucas pausas destinadas ao descanso, com refeições de curta duração e em lugares desconfortáveis, trabalham em turnos noturnos alternados ou iniciando muito cedo pela manhã, têm ritmos intensos ou monótonos e a pressão de supervisores ou chefias que impedem que o trabalhador obtenha controle do tempo de seu trabalho, gerando quadros ansiosos, fadiga crônica, distúrbios do sono (Jardim, Ramos, \& Glina, 2014).

Codo (2002) afirma que o sofrimento psíquico e o transtorno mental ocorrem quando o trabalho afeta esferas da vida que são geradoras e transformadoras de significados. Assim, existem fatores nocivos no trabalho, representados pelas condições de execução, pela sua organização e pelas relações simbólicas aí vividas. Nessa perspectiva, as instituições prisionais reúnem situações adversas que expõem os trabalhadores a cenários marcados por estresse extremo e contínuo, insegurança, relações hierárquicas rígidas, contato cotidiano com a violência, trabalho em espaços confinados e divisão em turnos - agravado pela prática da dobra de turno (Souza \& Rumin, 2013), cenário que pode desencadear sofrimento psíquico e uso abusivo de álcool e drogas.

De acordo com Lopes (2007), os agentes sofrem devido à ansiedade produzida pelo próprio ambiente e dinâmica de trabalho, pelo temor de serem atingidos pela violência, pela identidade fortemente marcada por aspectos pejorativos e sem reconhecimento social, bem como pela desvalorização da profissão, encontrando no uso de substâncias uma forma de socialização, de alivio de tais tensões e de compartilhamento de angústias.

Os efeitos do trabalho no cárcere já vêm sendo destacados na literatura como importante problemática junto a essa categoria profissional, a qual precisa ser mais bem investigada dada sua gravidade. Em uma pesquisa realizada no presídio estadual de Pelotas/RS, Chies, Barros, Lopes e Oliveira (2005) relatam uma série de mudanças nos hábitos e comportamentos de agentes penitenciários em decorrência do exercício de sua profissão. Segundo os autores, os APs apresentam mudanças quanto à exigência de disciplina de terceiros, de si próprio, quanto à forma de falar e de se vestir, passando a desconfiar mais das pessoas e a apresentar dificuldades em desenvolver novas relações de amizade e dificuldades no relacionamento com o cônjuge.

De acordo com Figueiró (2015), há a construção de um modo de vida entre os APs, que é marcado pela tensão e insegurança, obrigando-os a estarem vigilantes não somente dentro, mas principalmente fora da prisão. Os detentos - e sua rede de contatos -, enquanto sujeitos perigosos, constituem ameaça virtual fora dos muros da prisão, nas ruas, esquinas, semáforos etc. Assim, o trabalho como AP tem efeitos e produz modos de vida baseados no amedrontamento, o que produz graves limitações em relação ao lazer e vida social, especialmente em espaços públicos, além de importantes transformações na subjetividade desses trabalhadores. Segundo o autor,

A produção de agentes penitenciários, capacitados a lidar com detentos, de maneira firme e severa, ensina a esses trabalhadores não apenas procedimentos, mas uma maneira de habitar o mundo. Trata-se aqui de uma transformação de suas subjetividades, uma disciplinarização do corpo, na direção de uma "dureza", de uma subjetividade militarizada. Relembrando o diálogo com o AP que relata seus primeiros dias de trabalho, quando foi orientado a deixar seu coração do "lado de fora" da cadeia, a sensação é de que o conselho foi seguido à risca: "Eu era mais compreensivo, mais amável, e hoje em dia a mulher diz que eu não tenho mais coração". (Figueiró, 2015, p. 137)

O trabalho de custódia de presos se torna deveras complexo quando os APs se deparam com as dificuldades 
e precariedades observadas no sistema prisional. Borges (2014) aponta que é possível identificar associação entre o desenvolvimento de sintomas depressivos e três categorias de situações estressoras causadas pelo trabalho. A primeira é a falta de controle sobre os recursos organizacionais, principalmente a falta de controle moral sobre o trabalho. Algumas organizações solicitam aos empregados que tomem atitudes que diferem do padrão moral pessoal, impondo-lhes um controle sobre o trabalho que impede mudanças na organização dos processos de trabalho. A segunda categoria relaciona-se à imprevisibilidade, que pode assumir principalmente as formas de perdas do emprego e condições perigosas de trabalho. Já a última está relacionada aos conflitos interpessoais.

É possível constatar esses fatores estressores no trabalho no cárcere, pois o trabalho do AP está inserido em processos contraditórios que tornam a natureza da penitenciária duplamente difícil. Se o guarda cumpre as regras severamente, é diagnosticado pela população carcerária como mau, perseguidor, complexado, a comunidade carcerária vai tentar perturbar ou, pelo menos, não facilitar o desempenho das tarefas; a direção, considerá-lo-á inadaptado ao seu papel e classificará seu comportamento de inconveniente. Se o AP é menos exigente na estrita obediência ao quadro de normas regulamentares, será visto como relapso ou como infrator da ordem de que é o representante oficial (Sousa \& Rumin, 2013).

Outro fator que marca o trabalho dos APs e possibilita o surgimento de sofrimento é a ausência de sentido para o trabalho. As revistas de celas e dos visitantes em busca de drogas e artefatos proibidos têm revelado o quão impotente ficam diante da tarefa de manter o presídio livre desses itens. É consenso entre os APs o fato de que sempre houve e sempre existirão no interior da unidade prisional as drogas, celulares etc. $\mathrm{O}$ cotidiano prisional obriga os agentes a cumprir a dura tarefa de abrir as celas no início do dia, para depois trancá-los novamente em celas escuras e insalubres. Dessa forma, os trabalhadores de estabelecimentos prisionais vivem o drama diário de realizar um trabalho sem sentido, sempre "enxugando gelo", como aponta a pesquisa de Figueiró (2015).

Além disso, os APs realizam a contraditória tarefa de vigiar e castigar, ao mesmo tempo em que tentam gerar a ressocialização (Lourenço, 2010), tarefa que não vem sendo realizada e que não é possível no cenário atual das prisões (Lopes, 2007). Assim, os agentes são trabalhadores com sentimentos ambíguos: por um lado, a satisfação com o emprego, a estabilidade e o desenvolvimento financeiro; por outro, o medo, a angústia, a solidão, a ansiedade, a tensão física e emocional (Lourenço, 2010). Tudo isso resulta em condições propícias para o sofrimento.

Lourenço (2010), em sua tese de doutorado, cita dados de pesquisas por ele realizadas no Núcleo de Acompanhamento e Integração Psicossociológica da Escola de Administração Penitenciária de São Paulo, a partir das quais afirma que os agentes penitenciários eram "além de lesionados física e psicologicamente, tornados incapazes de viver uma vida digna e decente" (p. 70). Muitos, inclusive, morriam precocemente, dentro ou fora de seus locais de trabalho. A expectativa de vida dos funcionários das prisões é diminuída se comparada com outras categorias profissionais, variando de 40 a 44 anos. Entre as causas das mortes, impressiona o fato de que a maioria dos trabalhadores morreu devido a traumatismos e poli traumatismo, infarto do miocárdio e hemorragias (geralmente causadas por projéteis de arma de fogo ou perfuração por arma branca), totalizando $70 \%$ dos casos.

Enfim, como já ressaltado, estudos específicos sobre o sofrimento mental de APs e formas de enfrentamento ainda são escassos e o que existe são discussões mais amplas direcionadas aos profissionais da Segurança Pública (Souza, Schenker, Constantino, \& Correia, 2013; Minayo, Assis, $\&$ Oliveira, 2011). No entanto, pesquisas têm evidenciado alternativas utilizadas para minimizar esse sofrimento. Quando encontram possibilidades de transformação, os trabalhadores encontram fora ou dentro do trabalho alternativas para lidar com as consequências negativas da vivência institucional. Figueiró (2015) aponta que o dia a dia dos agentes revela maneiras de trabalhar e modos de habitar esse espaço que revelam possíveis saídas encontradas por esses trabalhadores na tentativa de recriar o trabalho (como a busca de atividades físicas como forma de lazer, o desenvolvimento de outra atividade não relacionada à área de segurança pública, fazer curso de graduação na universidade e a separação do tempo de trabalho dos momentos de tempo livre). Entre o que está prescrito para o agente (manter a segurança do presídio, evitar a entrada de drogas e demais artefatos proibidos e colaborar para a ressocialização) e o que de fato é possível ser feito no presídio há uma grande distância e o caminho encontrado pelos agentes revela o modo como estes recriam seu trabalho e suas funções. Esse cenário indica a necessidade de maior investimento em ações que visem possíveis transformações nos processos de trabalhos, assim como a atenção em saúde mental direcionada aos trabalhadores do sistema prisional, através de políticas e programas de saúde específicos direcionados às áreas da segurança pública e saúde coletiva.

\section{CONSIDERAÇÕES FINAIS}

Essa investigação teve por objetivo mapear o padrão de uso de álcool e outras drogas, assim como a prevalência de transtorno mental comum entre agentes penitenciários de um estado do Nordeste do Brasil. Embora a frequência de sujeitos que atingiram o ponto de corte para TMC se encontre dentro da média nacional $(23,57 \%)$, não é possível 
desconsiderar que tal quadro está associado com algumas variáveis, já que agentes que dobram turno, que possuem mais de 10 anos de profissão e que têm outra ocupação na área de segurança estão mais propensos a desenvolver TMC. Além disso, possuir outra ocupação na área de segurança e dobrar turno também possui associação positiva com uso nocivo de álcool e tabaco, o que indica que tais fatores devem ser analisados com mais cuidado na tentativa de propor estratégias de prevenção e promoção da saúde mental para essa categoria profissional. Outro fator que chama a atenção diz respeito ao tipo de unidade prisional. Os dados apontam que trabalhar em centros de detenção provisória possui associação positiva com o uso nocivo ou dependente de álcool e tabaco, indicando condições de trabalho problemáticas nesse tipo de unidades prisionais.
Embora haja associação entre as condições e organização do trabalho com o sofrimento psíquico dos agentes, não queremos com isso dizer que a simples mudança desses aspectos seria o suficiente para resolver a questão. O modo como as políticas de segurança pública têm se materializado nas últimas décadas, com superinflação da população carcerária, criminalização de pequenos delitos (a política da "tolerância zero") e constante afirmação de uma cultura do castigo tem colaborado para que se produza um sistema jurídico-penal adoecedor, seja para os presos, seja para os agentes responsáveis pela custódia destes. Aliás, estamos próximos de completar três séculos de existência de um sistema prisional que, além de não cumprir com os propósitos alardeados de ressocialização, também não produz bons resultados para seus trabalhadores.

\section{REFERÊNCIAS}

Alves, V. (2009). Condições de trabalho de funcionários penitenciários de Avaré-SP e ocorrência de transtornos mentais comuns (Dissertação de mestrado). Faculdade de Medicina de Botucatu, Universidade Estadual Paulista, Botucatu, São Paulo, Brasil.

Borges, L. H. (2014). Depressão. In D. M. R. Glina, \& L. E. Rocha (Eds.), Saúde mental no trabalho: Da teoria à prática (pp. 391-402). São Paulo: Roca.

Chies, L. A. B., Barros, A. L. X., Lopes, C. L. A. S., \& Oliveira, S. F. (2005). Prisionalização e Sofrimento dos Agentes Penitenciários: Fragmentos de uma pesquisa. Revista Brasileira de Ciências Criminais, 52, 264-283.

Creswell, J. W. (2007). Projeto de pesquisa: Método qualitativo, quantitativo e misto ( $2^{\mathrm{a}}$. ed.). Porto Alegre: Artmed/Bookman.

Codo, W. (2002). Um diagnóstico integrado do trabalho com ênfase em saúde mental. In M. G. Jacques \& W. Codo (Eds.), Saúde mental \& trabalho: Leituras (pp. 173-192). Petrópolis: Vozes.

Fernandes, R. C. P., Neto, A. M. S., Sena, G. M., Leal, A. S., Carneiro, C. A. P., \& Costa, F. P. M. (2002). Trabalho e cárcere: Um estudo com agentes penitenciários da Região Metropolitana de Salvador, Brasil. Cadernos de Saúde Pública, $18(3), 807-816$.

Figueiró, R. A. (2015). Cartografia do trabalho de agentes penitenciários: Reflexões sobre o "dispositivo prisão" (Tese de doutorado). Pós Graduação em Psicologia, Universidade Federal do Rio Grande do Norte, Natal, Rio Grande do Norte, Brasil.

Ghaddar, A., Mateo, I., \& Sanchez, P. (2008). Occupational stress and mental health among correctional officers: a cross-sections study. Journal of Occupation Health, 50, 92-98.

Goldberg, D., \& Huxley, P. (1992). Common mental disorders: A bio-social model. London, New York: Tavistock, Routledge.

Gonçalves, D. M., Stein A. T., \& Kapczinski F. (2008). Performance of the Self-Reporting Questionnaire as a psychiatric screening questionnaire: A comparative study with Structured Clinical Interview for DSM-IV-TR. Cadernos de Saúde Pública, 24(2), 380-90.

Henrique, I. F. S., Micheli, D., Lacerda, R. B., Lacerda, L. A., \& Formigoni, M. L. O. S. (2004). Validação da versão brasileira do teste de triagem do envolvimento com álcool, cigarro e outras substâncias (ASSIST). Revista da Associação Médica Brasileira, 50(2), 199-206.

Instituto Nacional de Ciência e Tecnologia para políticas públicas de álcool e outras drogas. (2013). II Levantamento Nacional de álcool e drogas. Recuperado de http://inpad.org.br/wpcontent/ uploads/2013/04/LENAD_ALCOOL_Resultados.pdf
Jardim, S. R., Ramos, A., \& Glina, D. M. R. (2014). Diagnóstico e nexo com o trabalho. In D. M. R. Glina, \& L. E. Rocha (Eds), Saúde mental no trabalho: Da teoria à prática (pp. 49-80). São Paulo: Roca.

Kalinsky, B. (2008). El agente penitenciario: La cárcel como ámbito laboral. Runa, 28, 43-57.

Lima, F. P., Blank, V. L. G., \& Menegon, F. A. (2015). Prevalence of mental and behavioral disorders in military police of santa catarina. Psicologia: Ciência e Profissão, 35(3), 824-840. https://dx.doi.org/10.1590/1982-3703002242013

Lopes, R. (2007). Psicologia Jurídica o cotidiano da violência: o trabalho do agente de segurança penitenciária nas instituições prisionais. Psicologia para América Latina, 0, 1-8.

Lourenço, L. C. (2012). Na frente das grades: Uma pesquisa com agentes penitenciários da região metropolitana de Belo Horizonte. In M. T. A. D. Coelho, \& M. J. Carvalho Filho (Orgs.), Prisões numa abordagem interdisciplinar (pp. 97-120). Salvador: EdUFBA.

Lourenço, A. S. (2010). O espaço de vida do Agente de Segurança Penitenciária no cárcere: entre gaiolas, ratoeiras e aquários (Tese de doutorado), Instituto de Psicologia, Universidade de São Paulo, São Paulo, São Paulo, Brasil.

Lucchese, R., Sousa, K, Bonfin, S., Vera, I., \& Santana, F. R. (2014). Prevalência de transtorno mental comum na atenção primária. Acta Paulista de Enfermagem, 27(3), 200-207. https://dx.doi. org/10.1590/1982-0194201400035

Luiz, T. D. (2003). Humanização do sistema carcerário brasileiro: A problemática do sistema atual (Monografia de bacharelado). Escola do Direito, Universidade Estadual de Montes Claros, Montes Claros, Minas Gerais, Brasil.

Minayo, M. C. S., Assis, S. G., \& Oliveira, R. V. C. (2011). Impacto das atividades profissionais na saúde física e mental dos policiais civis e militares do Rio de Janeiro (RJ, Brasil). Ciência \& Saúde Coletiva, 16(4), 2199-2209. Recuperado de http:// www.scielo.br/scielo.php?script $=$ sci_arttext\&pid $=$ S1413$81232011000400019 \& \operatorname{lng}=$ en\&tlng=pt. $10.1590 / \mathrm{S} 1413-$ 81232011000400019.

Rodrigues, E. P., Rodrigues, U. S., Oliveira, L. M. M., Laudano, R. C. S., \& Nascimento Sobrinho, C. L. (2014). Prevalência de transtornos mentais comuns em trabalhadores de enfermagem em um hospital da Bahia. Revista Brasileira de Enfermagem, 67(2), 296-301. https://dx.doi.org/10.5935/00347167.20140040

Santos, D. C., Dias, J. S., Pereira, M. B. M., Moreira, T. A., Barros, D. M., \& Serafim, A. P. (2010). Prevalência de transtornos 
mentais comuns em agentes penitenciários. Revista Brasileira de Medicina do Trabalho, 8(1), 33-38.

Skapinakis P, Bellos, S., Koupidis, S., Grammatikopoulos, I., Theodorakis, P., \& Mavreas, V. (2013). Prevalence and sociodemographic associations of common mental disorders in a nationally representative sample of the general population of Greece. BMC Psychiatry. 13, 163.

Souza, J. C., \& Rumin C. R. (2013). O serviço de atenção à saúde mental aos trabalhadores do sistema prisional. Revista Transformações, 3(1), 00. Recuperado de http://www.ip.usp. $\mathrm{br} /$ portal/index.php?option $=$ com_content $\& v i e w=$ article\&i d=1923:v3n1a05-o-servico-de-atencao-a-saude-menta-aostrabalhadores-do-sistema-prisional \&catid $=340 \&$ Itemid $=91$

Souza, E. R., Schenker, M., Constantino, P., \& Correia, B. S. C. (2013). Consumo de substâncias lícitas e ilícitas por policiais da cidade do Rio de Janeiro. Ciência \& Saúde Coletiva, 18(3), 667-676. Recuperado de http://www.scielo.br/scielo. php? script $=$ sci_arttext\&pid $=$ S141381232013000300012\&ln $\mathrm{g}=$ en\&tlng=pt. 10.1590/S1413-81232013000300012.

Varella, D. (2012). Carcereiros. São Paulo: Cia. Das Letras.

Vasconcelos, A. S. F. (2000). A saúde sob custódia: Um estudo sobre agentes de segurança penitenciária no Rio de Janeiro (Dissertação de mestrado). Fundação Oswaldo Cruz, Escola Nacional de Saúde Pública, Rio de Janeiro, Rio de Janeiro, Brasil.

World Health Organization. (2002). ASSIST Working Group. The alcohol, Smoking and substance Involvement Screening Test (ASSIST): Development, reliability and feasibility. Addiction, 97(9), 1183-1194.

World Health Organization. (1994). User's guide to self-reporting (SRQ). Geneva: Author. 